\title{
Major Influencing Factors of Language Development: Students' Developing Second and Foreign Languages
}

\author{
Md. Faruquzzaman Akan \\ Lecturer in English-King Khalid University-Abha-KSA \\ f. akan@yahoo.com
}

\begin{abstract}
The aim and objective of this research is to find out the language students' factors, the contexts' factors, their influences on the whole process of language development and finally to look for some possible solutions. It is worth mentioning that a particular factor can be a barrier for one student although it may facilitate the other. However, there is no denying the fact that developing a new language, for example, a second or foreign language, is basically a complex and tiring job. According to Professor Stephen D. Krashen, we have two widely known and well-accepted means to develop language: 'acquisition' and 'learning'. Acquiring language is a natural process, whereas learning language is a training-based activity. During the time of language development, students confront various issues or factors viz. personal, biological, social, political, cultural, economic, academic and so on. Further researches show that after puberty or the critical period, students face some issues and there are facts that all individuals are different from one another. In the early 1960's, there was an upsurge of interest in individual characteristics. All these issues that affect developing language can broadly be categorized as internal and external factors. To assist the students of language, their initial errors in developing language should be allowed and corrected with a tact and sympathy. So, to discover a short-cut remedy for removing and/or minimizing all factors of language developers and teaching the target language is not an effortless work.
\end{abstract}

Keywords: students' factors, contexts' factors, acquisition, learning, puberty, UG, LAD, LLD

\section{Introduction:}

The very tool or instrument employed to express our feelings, ideas, thoughts, experiences and the like is the production of human sounds which are broadly known as language. Although we traditionally define the term 'language' as an arbitrary system, method or means of human communication and/or interaction, either spoken or written, that uses random signals, such as voice sounds, gestures or written symbols. But it is much more complex, cagey as well as captivating that cannot be made clear by a succinct definition. To interact with other people, all of us have to pick up or try to pick up some language from the early periods of our lives. What is surprising, according to the linguistics expert Professor Noam Chomsky who has developed and popularized the concept of Universal Grammar (i.e. UG) is that one can grasp one or more languages if $\mathrm{s} /$ he grows up hearing them spoken consistently as a real life exposure. But after puberty (i.e. the critical period, approximately at/before the age of fourteen) while developing a new language, a student encounters some issues or factors those affect developing language. In this study, the target language will refer to a second and a foreign language. So, the aim and purpose of this study is to identify the students' factors and contexts' factors; their functions and finding out some suitable solutions to developing a new language.

To develop or master any language is primarily a complicated brain activity and a tiresome task along with some other obstacles that affect and/or influence a student to achieve his or her goal. There are, for students to learn language, several issues or factors namely personal, social, biological, political, cultural, economic, curricular etc that must be considered because all these play a pivotal role in the speed and acquisition of the new language. Before discussing these issues, let us concentrate on how to develop a language or the ways of language development. Made 
popular and well-ccepted by a prominent linguist Professor Stephen D. Krashen, there are two distinctive ways or means - acquisition and learning - to develop language. The 'AcquisitionLearning' distinction is the most fundamental of all the hypotheses in Krashen's theory which is most expansively known among linguists and language practitioners. We know 'acquiring' language results from immersion which is a natural process involving a constant exposure to the language, whereas 'learning' language refers to studying the language's rules, structures and vocabularies which is done by some formal training and supervision. The first one is a subconscious and the later one is a conscious process. Here, we may show what acquisition and learning exactly mean in developing language by quoting Ellis (1985:6), "The term 'acquisition' is used to refer to picking up a second language through exposure, whereas the term 'learning' is used to refer to the conscious study of a second language".

Furthermore, a distinction is often made between competence and performance in the study of language. According to Chomsky (1965), competence consists of the mental representation of linguistic rules which constitute the speaker-hearer's internalized grammar, while performance consists of the comprehension and production of language. Language acquisition studies - both first and second-are interested in how competence is developed. However, because second language acquisition focuses on performance, there is no evidence for what is going on inside the student's head. This is one of the major flaws of the research in second language acquisition.

\section{Acquisition:}

Acquisition is a component of the Nativist theory of language in which one develops a second or foreign language in the same way as s/he picks up the mother tongue. It is a natural or subconscious process that usually takes place before puberty. Krashen (1982:10) states, "The result of language acquisition ... is subconscious." In the 1960's, Chomsky first proposed the concept of Language Acquisition Device (LAD) that is an instinctive mental capacity which enables an infant to acquire and produce language. Chomsky's theory proposes that the human brain contains a predefined mechanism known as UG that is the basis for the acquisition of all languages. That is, humans are born with the innate facility or instinct for acquiring language. One piece of evidence for the existence of an LAD is the fact that some physical areas, specially the left hemisphere of the human brain concerned with production and comprehension have been identified. In accordance with Chomsky, the human mind is inhabited by a specific module which handles language. Seen from the point of view of language acquisition, the UG is linked to the LAD- the Language Acquisition Device- which can be thought of as a programmer which enables the child to set the parameters of the UG on the basis of what s/he hears speakers say around him or her. Afterwards, Krashen made this idea popular and developed it a lot in the field of language acquisition. According to his hypothesis, 'acquisition' is the product of a subconscious process very similar to the process children undergo when they acquire their first language. Language acquisition occurs subconsciously while participating in natural conversations or communications where the focus is on meaning. So, it is stated according to Krashen (1996),

\section{Acquisition necessitates the natural communication through the meaningful interaction in the target language where speakers are concerned not with the form of their utterances but with the messages they convey and conceive.}

To acquire a second or foreign language, it involves four basic skills of language: listening, speaking, reading and writing. Here, listening and reading are termed as receptive skills; speaking and writing as productive skills. It is believed that receptive skills create productive skills within a student. So, the total amount of linguistic input produces almost equal linguistic output after processing with Language Acquisition Device. Language acquisition process can be shown in the following way: 


\section{Input}

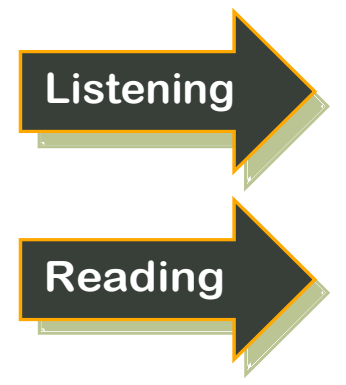

Output

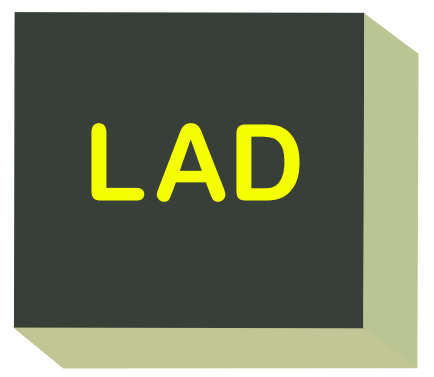

\section{Speaking}

\section{Writing}

\section{Learning:}

The learning of language is a conscious way that occurs separately where grammar, vocabulary, and other rules about the target language are explicitly taught and developed. There is a focus on analyzing errors and correcting them. The focus in the aspect of learning is not on the content or meaning of the conversation or book, but rather on the structure of the language. It refers to reading about and memorizing the rules of the target language through language lessons and a focus on the grammatical features of that language. Unlike acquisition, it requires a formal training. As per Krashen's hypothesis, learning is the product of formal instruction and it comprises a conscious process which results in conscious knowledge 'about' the language, for example, the knowledge of grammatical rules. According to Krashen, learning is less important than acquisition but so far as grammatical accuracy is concerned learning is superior to acquiring language. We could rephrase Krashen's (2009) statement here on learning,

\section{Nontechnically, learning is 'knowing about' language which is known to most people as 'grammar' or 'rules'. It may include formal knowledge or explicit meaning of language.}

For developing a new language after puberty or the critical period, learners are much influenced by some significant factors, such as age, aptitude, personality, motivation, cognition etc specially to master the four basic skills of language. In the process of developing 'learning', we can think of a hypothesis that could be termed as Language Learning Device (LLD) for a child or an adult to process a number of things as linguistic inputs or encodes. As humans are limited-capacity processors, they manage to make the most of their limited processes in dealing with the complex inputs of a second language. So, the whole thing of processing the linguistic input and the production of language as a linguistic output may be represented in the diagram below:

\section{Input}

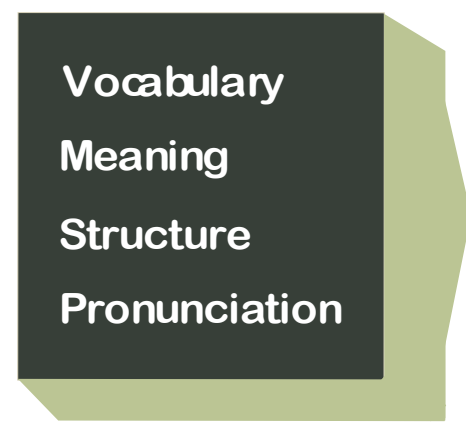

\section{Output}

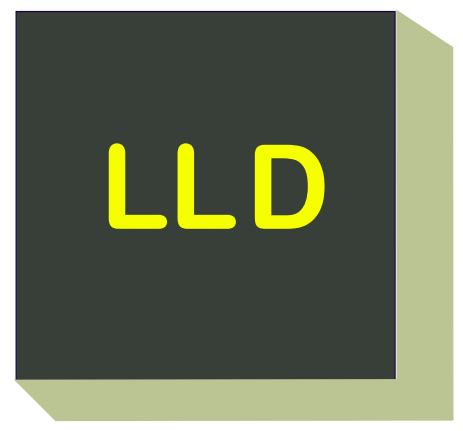




\section{The Human Brain and the CPU:}

The human brain can logically be compared to the Central Processing Unit (CPU) of a computer but it is more superior. Information enters the brain as an input, gets processed and finally comes out as an output. There are three major input ways: the eyes (for sights/written symbols), the ears (for hearing/voice sounds) and the hands (for touches/gestures). In terms of input variation, students are mainly classified as: visual, auditory and kinesthetic. Sights are more important for better retention of the visual learners. For developing listening and speaking, the use of hearing ability is undoubtedly helpful for auditory learners. Margaret H'Doubler wrote and spoke about kinesthetic learning during the 1940's, defining kinesthetic learning as the human body's ability to express itself through movement and dance. There is a fourth type of student known as a reading or writing-preference learner. Here, the picture of the left part of the human brain which is responsible for the production of language is sown below:

\section{Left Hemisphere of the Human Brain}

\section{Types of Learners}

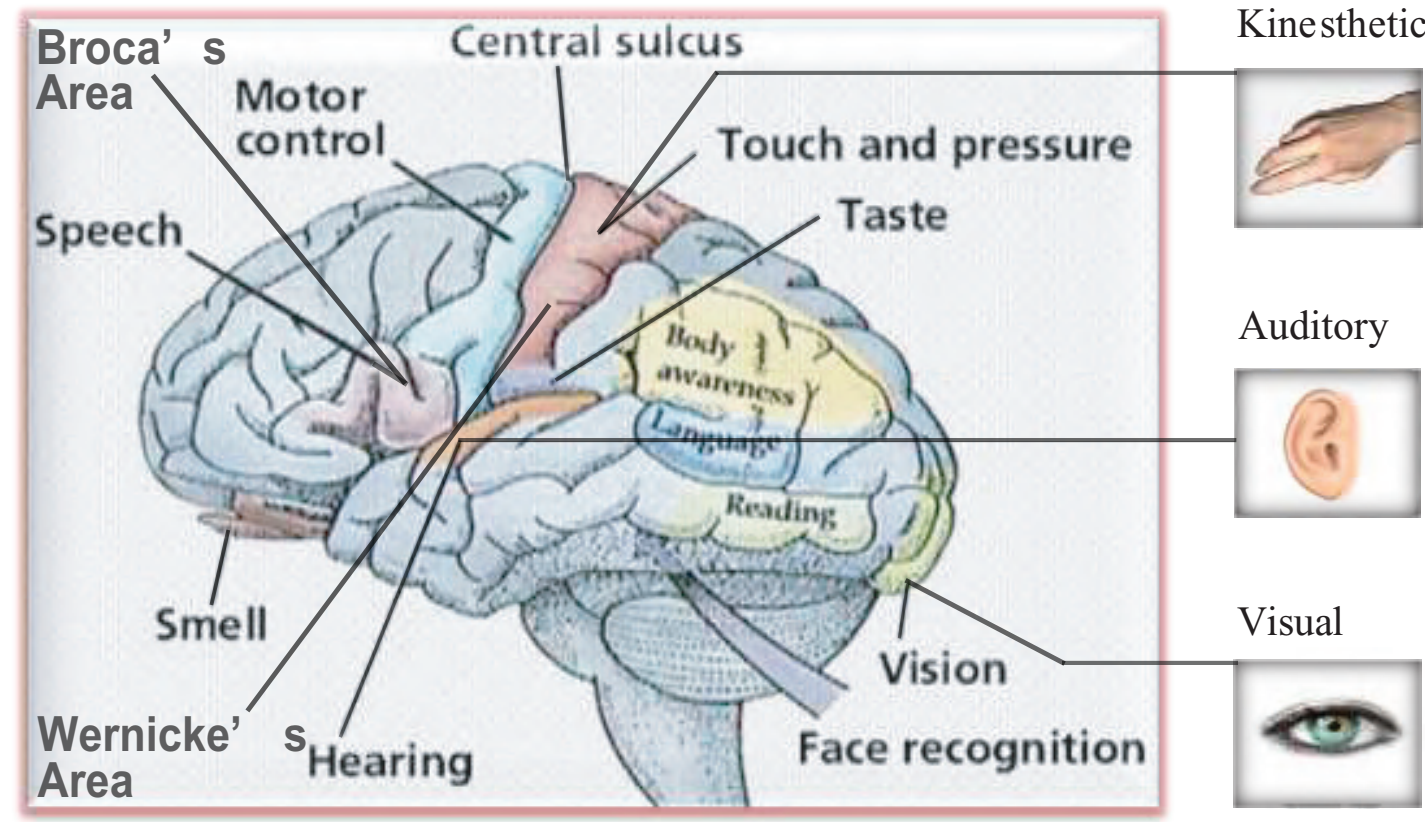

\section{Individual Differences:}

All students or language developers do not usually behave or think identically. So, one may develop a new language more quickly and easily than others. They are successful by virtue of their sheer determination, hardwork, persistence, attention and willingness. But there are other issues that influence language developing. These crucial issues or factors influencing success are largely beyond the control of the students. Despite the best intentions of both the teacher and the students, they encounter a number of barriers to language development in a classroom or elsewhere. We all know that we are different from each other in many ways, such as our physical aspects, psychological make ups, likings, dislikings, interests, values etc. According to the study of Murray and Kluckhohn (1953), all people are at three levels of focus that can be expressed by the following well-known quote:

"Every man is in certain respects-"

(a) like all other men,

(b) like some other men and

(c) like no other man. 
As further researches show that after puberty, students face some problems for developing a new language. There are some facts or issues that make people different from each other. For these factors- some students learn a new language more quickly and easily than others. In the early 1960's, there was an upsurge of interest in individual characteristics. Though some cope more easily with learning activities, materials and so forth than others, no generalization can be made about these. These issues can be broadly categorized as internal and external factors. The external factors are greater in number than the internal factors. So, here we will try to discuss these major factors influencing the whole process of language development.

\section{Internal Factors:}

The internal factors are those that an individual student brings wtih him or her to a particular language developing situation. These are the some traits of students which are very personal, permanent, unchangeable or difficult to change. These are, in linguistics, known as 'Individual Differences'. However, these factors are comparatively limited and short-listed but we cannot change them- not all but most of them. For example, age, aptitude, personality, motivation, intelligence, experience, cognition/cognitive style, native language, gender etc.

- Age: Language acquisition is influenced by the age of the student. Wilder and Lamar (1959) argue that the optimum age of language acquisition falls within the first ten years of life. So, before puberty the language developing process is quicker than latter ages. A common belief is that students having solid literacy skills in their native language seem to be able to acquire a new language easily and efficiently. But if motivated, older learners can be very successful too, but do not achieve the native-speaking pronunciation and intonation that younger children naturally do.

Older students are better in rate and success of second language acquisition. Snow and Hoefnagel-Hole (1978) found that age was a factor only when it came to morphology and syntax. However, the common concept is that children are superior to grown up people in pronunciation.

- Aptitude: In general, aptitude refers to the disposition of the student to be able to do something well. Everyone does not have the same or specific aptitude or talent. But aptitude can be expected to influence the rate of language development, particularly where the formal classroom training is concerned. Carroll and Sapon (1959) identify three major components of aptitude: a) phonetic coding ability, b) grammatical sensitivity and c) inductive ability.

- Motivation: The term motivation means the students' willingness to do something. It plays a significant role in language achievement. The higher the level of motivation is, the harder the student will work and the longer he or she will persist. If a student enjoys developing language or takes pride in his or her progress will do better than those who don't. Intrinsic motivation has been found to correlate strongly with educational achievement. Extrinsic motivation is also a significant factor. ESL students, for example, who need to develop English in order to take a place at an American university or to communicate with a new English friend is likely to make a greater effort and thus have a greater progress. Much motivated students used more learning strategies, and more frequently (McIntyre and Noels, 1996).

- Personality: In general psychology, personality has been explored in terms of a number of personal traits, which in aggregate are said to constitute the total identity of an individual. There are two main types of personality: introvert and extrovert. Extrovert students are quicker than the introvert ones. Introverted or anxious students usually tend to make slower progress, particularly in the development of oral skills. More outgoing students will not worry about the inevitability of making mistakes. They will take risks, and thus will give themselves much more practice. The Myers-Briggs Type Indicator (MBTI) is an instrument widely used to help people discover the way they tend to take in information, make decisions and relate to people.

- Intelligence: Intelligence is the term used to denote a hypothesized 'general factor', which underlies the ability of a student to master and use a whole range of academic skills. It is the 
underlying ability to achieve rather than the actual knowledge that is supposedly measured by intelligence tests (McDonough, 1981). Though students' intelligence should never be a factor in deciding whether or not to try something new, it does affect their foreign language learning ability. If students are highly intelligent when it comes to language-oriented tasks, developing a second language will be easier for them. It is less likely to influence the acquisition of oral fluency skills.

- Cognitive style: Cognitive styles refer to the manner in which people perceive, conceptualize, organize and recall information. Messick (1970) describes it, for the most part, as information processing habits.

In general, students with greater cognitive abilities or general aptitudes will make faster progress. Some linguists believe that there is a specific, innate language developing ability that is stronger in some students than others. They can grasp language patterns and structures more easily. They are quicker to acquire new words. They are more fluent speakers and writers of their new language. Cognitive and meta-cognitive strategies show high correlation with high language proficiency levels (Peacock and Ho, 2003).

- Experience: Students who have acquired general knowledge and experience are in a stronger position to develop a new language than those who haven't. The student who has lived in other countries and/or has been exposed to travels, diverse cultures, and languages has a stronger base for achieving than the student who hasn't had such experiences. Most educators understand the important role that the experience plays in the learning process. Studying abroad contributed to language learning strategies choices (Opper, Teichler and Carlson, 1990).

- Native language/Mother tongue: Native language always plays a great role in a second and foreign language developing. Students who are developing a second language which is from the same language family and may even use the same alphabet system and many of the phonetic sounds as their first language has, in general, a much easier task than those who aren't. So, for example, a Dutch child will learn English more quickly than a Japanese child. In some other cases where a learner is of a quite different language, his or her mother language acts as a barrier to achieving the target language.

- Gender: The study of language and gender has developed greatly since the 1970's. As per the so-called 'dominance approach', gender differences in language reflect 'power differences' in the society. But till now, the findings are in some cases inconclusive to show the exact role of sex in language developing. Some research projects have yielded evidence that women tend to be more active strategy users than men (e.g. Oxford and Nyikos, 1989, Dreyer and Oxford, 1996), but the others have failed to corroborate the existence of such gender related differences (e.g. Griffiths, 2003). There is a common belief that men are good at 'analysis' and women are quick at 'memorizing'. Females use significantly more learning strategies than males, although sometimes males surpass females in the use of a particular strategy (Green and Oxford, 1995).

\section{External Factors:}

The factors those are prevailing in the context of language developing and teaching are external factors. These characterize the particular language developing situation. These factors are impersonal, changeable or temporal which impede the process of learning the target language. All the external factors are well-nigh impossible to explore in a short span of time. However, some more significant of them are mentioned here. For example, teacher, syllabus, curriculum, instruction, culture and status, class size, encouragement etc.

- Teacher/Instructor: Some language teachers are better than the others in providing appropriate and effective learning experiences for the students in their classrooms. These students will make faster progress. It applies to mainstream teachers in second language situations. Teachers who naturally differentiate content and provide needed language supports help contribute greatly to these children's linguistic development. 
- Syllabus: A syllabus is a set or collection of training content for a comparatively short timespan. A need based and well-described syllabus always influences the promotion of achieving. For ESL students in particular, it is important that the totality of their educational experience is appropriate to their needs. Unfamiliar things are to be taught in a very interesting way so that they can get involved easily.

- Curriculum: A curriculum is a nation-wide as well as long term educational policy. Allowing the students to gain language from all curricular areas is the key to language success. Language developers are less likely to take place if students are fully submersed into the mainstream programme without any extra assistance or, conversely, not allowed to be a part of the mainstream until they have reached a certain level of language proficiency.

- Class size: Class sizes are important factors for successful language development and teaching because many educational institutions have a very large number of students with a single teacher. Researchers have found that gains in language achievement generally occur when a class size is reduced to less than 20 students. But the optimum size may be from 20 to 25 students with a single instructor.

- Culture and Status: There is some evidence that students in situations where their own culture has a lower status than that of the culture in which they are developing the language make slower progresses.

- Encouragement: Students who are given continuous and appropriate encouragement by their teachers and parents to study will be generally far better than those who aren't. For example, students from families that place little importance on language developing are likely to progress less quickly than those who aren't.

- Group discussion: Exchange of ideas and thoughts before and after the lecture is helpful to develop language. It also develops the power of expression. Learners who favour group study tend to use social and interactive strategies (Rossi-Le, 1995).

- Access to native speakers: The opportunity to interact with native speakers both within and outside the classroom is a significant advantage. Native speakers are probable linguistic models and can provide appropriate feedbacks for the students.

- Teachers' expectation: A teacher's expectations of his or her students can create a barrier to the students' achieving. If you don't believe a particular student is capable of achieving a certain goal, you may not provide the support necessary for him or her to do it, thereby unconsciously ensuring that he or she doesn't.

- Classroom management: A classroom that is loud and disorderly can create a barrier to students' training. Good classroom management can end bad behavio ur before it begins, and offers both students and the teacher direction for discipline to ensure the unwanted behavior doesn't continue. To have a clear plan for managing your classroom, and discussing the rules and the consequences for breaking your rules at the beginning of the year works well. Students should be asked for feedbacks on the rules, and listen to their concerns.

- Students' interest: Training can only occur when students are engaged and interested in the lesson and the information they're achieving. To make students interested, lessons should be designed to keep them active, such as group activities, presentations and experiments etc.

- Students' confidence: Students' beliefs about their abilities can greatly affect their academic achievement. Those who lack self-confidence won't try hard in the classroom because they imagine their failure is imminent, so they see no reason to try. Self-confidence plays a larger role in developing a second language than it does in developing other subjects. Those who lack confidence can be afraid of making mistakes, which are an important part of language development.

After passing through Language Processing Device (LPD), the internal and external factors emerge outputs as acquisition and learning. The whole process can be represented in the diagram on the following page: 


\section{Input}

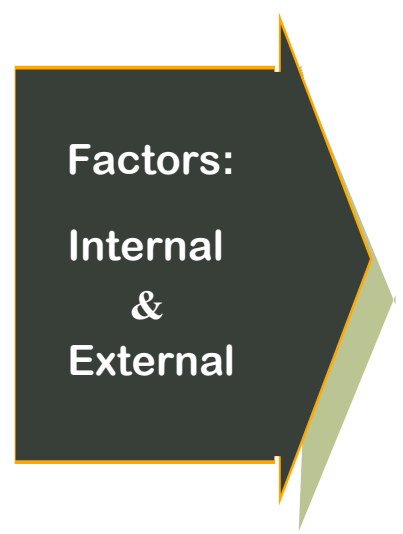

Output

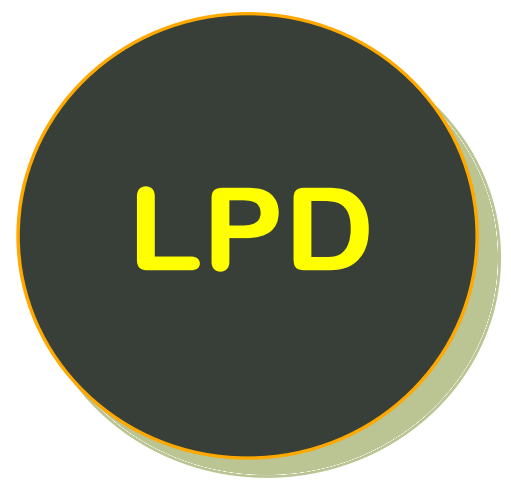

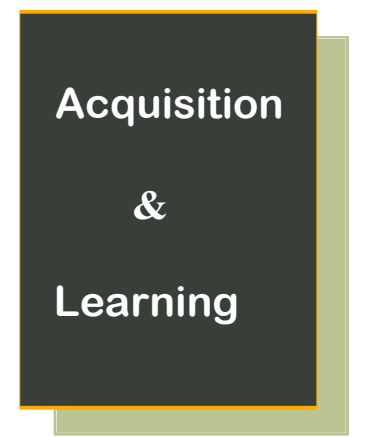

Suggestion: In this part of the study, some suitable and possible solutions to overcome the barriers to devoloping language is to be tried to find out. McCauley and McCauley (1992) report four factors as necessary for acquiring a second language: a low-anxiety environment, repeated practice, comprehensible input and drama. Here, each of these items is elaborated in the following way:

[1] A low-anxiety environment: It includes a setting where students feel nurtured and supported by their teachers and peers, and in turn, they feel safe to take risks without the fear of being laughed at, outnumbered or made fun of.

[2] Repeated practice: Students require repeated practice of hearing and using a new language. They need multiple opportunities to comprehend and express their ideas in that language. Like with anything new that we achieve, practice helps us get better.

[3] Comprehensible input: It means finding different ways to make what is being said comprehensible and easy to understand. Things to consider with comprehensible input might include using speech that is appropriate to students' language proficiency, providing a clear, step-by-step explanation of tasks, and using a variety of techniques to support their understanding.

[4] Drama: It refers to a sense of excitement and engagement that can be found in activities in a dramatic play, puppetry, narrating wordless picture books, etc.

All of these activities also have some other (three) factors embedded within them. These activities assist in the development of oral language in addition to introducing students to oral reading and rich literacy experiences and responses in a classroom setting. First, we can aim at the development of four basic skills of language and this should be done at a very early stage of the learners:

$\nabla$ Listening: Through the normal course of a day, listening is used nearly twice as much as speaking and four to five times as much as reading and writing (Rivers, 1981). So, listening to an exact or nearly exact accent is helpful possibly with visual supports. A student's interest in a topic increases comprehension.

Q Speaking: When students do not speak, they are in a silent period in which they listen. Students in the silent period should not be forced to speak, but should be given the opportunity to participate in a group activity where they won't be singled out. They start using one or two-word phrases and produce simple sentences for their basic needs. Students should be encouraged to begin taking risks in non-threatening situations.

$\nabla$ Reading: Students are to be encouraged to agree or volunteer to participate in both discussion and reading aloud. However, they should never be called on or requested to share unless they are 
prepared or volunteered. After a couple of weeks of feeling comfortable sharing in small groups and observing his/her peers share in a whole group setting. The opportunities to share a whole group were always preceded by discussion and practice with partners and/or small groups.

Q Writing: Writing is, no doubt, the most complicated of all the four skills to master. So, the students should be well prepared and motivated enough before they start writing. All types of grammatical and spelling errors are to be considered as a part of learning and to keep them writing a lot on various topics.

\section{Here, we could advocate some more steps to follow to achieve the goal:}

- To put highly meaningful words in the beginning than the less meaningful ones to develop easily

- To maintain serial position like placing items at the beginning or end of the list rather than in the middle

- Repeated and active practices or rehearsals to improve retention

- To transfer effects of prior learning on the achieving of a new material

- To recall freely to be better when learners organize the items into categories rather than attempt to memorize the list in serial order

- Associating the input with more meaningful images or semantic contexts

- To make learning state or context-dependent because language development takes place in within a specific context that must be accessible later

- To learn the parts that occupy higher levels in the organization of the passage to be developed better than parts occupying lower levels

- To concentrate on the main ideas and to retain these in semantic forms rather than the specific words of a sentence

- To organize a text that assists learning in retaining information, such as previews, logical sequencing, outline formats, highlighting of main ideas and summaries to help students

- To make scope to employ prior knowledge that will occur to the extent that the student can use existing knowledge to establish a context or construct a schema into which the new information can be assimilated etc.

\section{Conclusion:}

To conclude, it could be very correctly affirmed that finding out a short-cut solution to developing a new language is not an easy task. As per the above analyses, we have exactly a little scope to do anything with the internal factors. But the external factors could be minimized to some extent yet they are greater in number. To make the process of developing a second or foreign language faster and more successful, it should be started as soon as possible in a student's early life, books should be entertaining along with information, the class size is to be optimal as per the course, there must be a very good rapport between the teacher and the students etc. As students between the ages of 5 and 18 years old are expected to study in a school, it is the teachers' primary job to prepare them to become productive members in their adult years. What they learn will also determine the choices they will make when they enter the workforce or continue onto higher education. In order for students to learn, there are several factors that must be considered, for examples, students' personal, biological, social, political, cultural, economical, academic etc. This may be determined by the school's environment as well as the teachers and administrators that teach them. The same factor 
may not be a barrier for different types of students. Each learning obstacle is faced in a different way by each student with each learning goal. When the action plan is going to be done, there may not be any 'right' way to remove each obstacle. So, getting help from families, friends, co-workers, supervisors and trainers in generating ideas to overcome and/or remove the obstacles could be a way out. Still, another important factor falls upon a student's ability and willingness to learn. In this case, language developing should be entertaining and some latest teaching approaches may be applicable for them. Concerning language development, three main theories have been approached from different perspectives to answer the question of how language is developed. Thus, 'behaviorism' puts emphasize on the essential role of the environment in the process of language development, whereas 'mentalist theories' give priority to the students' innate characteristics from a cognitive and psychological approach. A third approach claims for relevant concepts such as a comprehensible input and a native speaker interaction in conversations for students to acquire the new language.

As language development and teaching are a downright practicalwork, it requires real life exposures and training for the teacher is a must for him or her to be a role model for the students. Here, native speakers could be a good option. But there should not be any compromise regarding teachers' linguistic competence. But at the very beginning, communicative competence may be developed at the cost of accuracy. However, the teacher should be prepared to be flexible in incorporating new ideas and concepts in the classrooms about the process of developing the target language. There is no denying the fact a student should be both accurate and fluent. So, it is in no way possible to say, in particular, this or that is a clear-cut or easy solution to solving all the problems involved in the language developing or teaching process.

\section{References:}

[1] H. D. Brown, (1994). Principles of Language Learning and Teaching, 3rd ed. Englewood Cliffs, N.J.: Prentice Hall Regents.

[2] H. D. Brown, (2007). Principles Of Language Learning And Teaching. White Plains, NY.: Addison Wesley Longman.

[3] G. Brown and G. Yule, (1983). Teaching the spoken language. Cambridge: Cambridge University Press.

[4] K. Berger, (2008). The Developing Person Through the Lifespan. $7^{\text {th }}$ Edition. New York: Worth.

[5] A. Baugh, and T. Cable, (1993). A History of the English Language. Prentice-Hall Editions.

[6] S. Corder, (1981a). Error Analysis and Interlanguage. Oxford: Oxford University Press.

[7] D. Crystal, (1985). Linguistics. Harmondsworth, England. Penguin Books.

[8] R. Ellis, (1994). The Study of Second Language Acquisition. Oxford University Press.

[9] R. Ellis, (1985). Understanding Second Language Acquisition. Oxford University Press.

[10]C. M. Ely, (1988). "Personality: Its Impact on Attitudes toward Classroom Activities," in Foreign Language Annals 21(1): 25-30.

[11]C. Ferguson, \& H. Thom, (1989). "Foreign Language Instruction and Second Language Acquisition Research in the United States." Occasional Paper published by the National Foreign Language Center, Washington, D.C.

[12]T. E. Good, and J. E. Brophy, (1986). Educational Psychology: A Realistic Approach, Third edition. Longman Publishing, New York.

[13]R.C. Gardner, R.C. Lalonde, and R. Moorcroft, (1985). "The Role of Attitudes and Motivation in Second Language Learning: Correlational and Experimental Considerations," in Language Learning 35: 207-227.

[14]A. Z. Guiora, \& R. A. William (1979). "Personality and Language Behavior" in Language Learning 29: 11-24.

[15]E. R. Hilgard, \& G. H. Bower, (1975). Theories of Learning: Fourth Edition. Prentice-Hall, Inc. Englewood Cliffs, NJ.

[16]A. Howatt, (1984). A history of English Language teaching. Oxford: Oxford University Press. 
[17]H. Hadley, (2002). Reviewing first and second language acquisition: A comparison between young and adult learners. Niigata Studies in Foreign Languages and Cultures, (8), 37-48.

[18]K. Hakuta, (2001). A Critical Period for Second Language Acquisition?. In Bailey, D., Bruer, J., Symons F., and Lichtman, J. (Ed.), Critical Thinking about Critical Periods. (pp. 193205).Baltimore: Paul Brookes Publishing.

[19]S. D. Krashen, \& T. D. Terrell, (1983). The Natural Approach: Language Acquisition in the Classroom. Oxford: Pergamon.

[20] S. D. Krashen, (1996). Under attack: The case against bilingual education, Language Education Associates, Culver City, California, USA.

[21] S. D. Krashen, (2009). Principles and practice in second language acquisition, 1st internet edn. Oxford.

[22]P.M. Lightbown, and N. Spada, (2013). How Languages Are Learned. Oxford: Oxford University Press.

[23]E. Macaro, (2010). Continuum Companion to Second Language Acquisition. London: Continuum, Print.

[24] R. Mitchell, F. Myles, and E. Marsden, (2013). Second Language Learning Theories. (3rd ed.) London: Routledge.

[25]W. Rivers, (1981). Teaching Foreign-Language Skills (2 ${ }^{\text {nd }}$ Edn). Chicago: University of Chicago Press.

[26]J. Richards, and T. Rodgers, (1992). Approaches and Methods in Language Teaching ( $2^{\text {nd }}$ ed.). Cambridge: Cambridge University Press.

[27]J. Richards, (1983). Listening comprehension: Approach, design, procedure. TESOL Quarterly.

[28]J. C. Richards, and T. S. Rodgers, (1986). Approaches and Methods in Language Teaching, OUP.

[29]P. Skehan, (1989). Individual differences in second language learning. London: Edward Arnold.

[30]L. White, (2003). Second Language Acquisition and Universal Grammar. CUP.

[31] G. Yule, (2010). The Study of Language (4th ed.). Cambridge, UK: Cambridge University Press. 